\title{
Telepsychiatry Adoption Across Hospitals in the United States: A Cross- Sectional Study
}

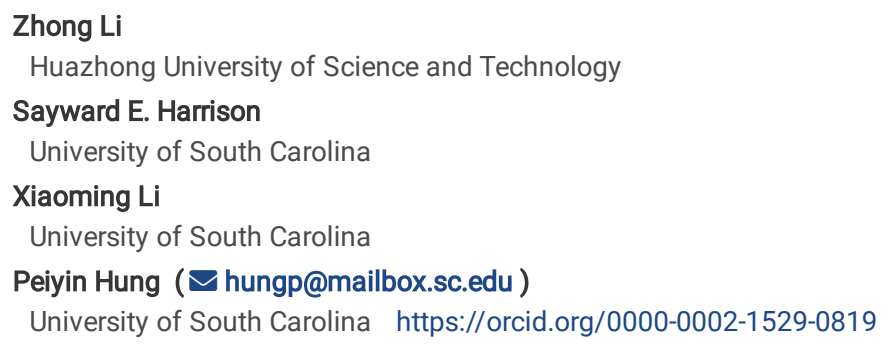

\section{Research article}

Keywords: Telepsychiatry, Telemedicine, Hospital psychiatry, Access to care, Continuity of care

Posted Date: August 21st, 2020

DOl: https://doi.org/10.21203/rs.3.rs-58005/v1

License: (c) (i) This work is licensed under a Creative Commons Attribution 4.0 International License. Read Full License

Version of Record: A version of this preprint was published at BMC Psychiatry on April 7th, 2021. See the published version at https://doi.org/10.1186/s12888021-03180-8. 


\section{Abstract}

\section{Background}

Access to psychiatric care is critical for patients discharged from hospital psychiatric units to ensure continuity of care. When face-to-face follow-up is unavailable or undesirable, telepsychiatry becomes a promising alternative. This study aimed to investigate hospital-and county-level characteristics associated with telepsychiatry adoption.

\section{Methods}

Cross-sectional national data of 3,475 acute care hospitals were derived from the 2017 American Hospital Association Annual Survey. Generalized linear regression models were used to identify characteristics associated with telepsychiatry adoption.

\section{Results}

About one-sixth (548 [15.8\%]) reported having telepsychiatry. Rural noncore hospitals were less likely to adopt telepsychiatry (8.3\%) than hospitals in rural micropolitan (13.6\%) and urban counties (19.4\%), with a wide variation across states. Hospitals with both outpatient and inpatient psychiatric care services (marginal difference [95\% Cl]: $16.0 \%$ [12.1\% to $19.9 \%]$ ) and hospitals only with outpatient psychiatric services $(6.5 \%$ [3.7\% to $9.4 \%]$ ) were more likely to have telepsychiatry than hospitals with neither psychiatric services. Federal hospitals (48.9\% [32.5\% to 65.3\%]), system-affiliated hospitals (3.9\% [1.2\% to $6.6 \%]$ ), hospitals with larger bed size (Quartile IV vs. I: $6.2 \%$ [0.7\% to 11.6\%]), and hospitals with greater ratio of Medicaid inpatient days to total inpatient days (Quartile IV vs. I: $4.9 \%$ [0.3\% to 9.4\%]) were more likely to have telepsychiatry than their counterparts. Private non-profit hospitals (-6.9\% [-11.7\% to $-2.0 \%]$ ) and hospitals in counties designated as whole mental health professional shortage areas $(-6.6 \%[-12.7 \%$ to $-0.5 \%])$ were less likely to have telepsychiatry.

\section{Conclusions}

Telepsychiatry adoption was low in US hospitals in 2017 with substantial variations by urban and rural status and by state. It raises concerns about access to psychiatric services and continuity of care for patients discharged from hospitals.

\section{Background}

Over 46 million Americans experienced a mental illness (1); however, less than half (42.9\%) of these individuals received mental health services in a 12-month window, partially due to stigma and limited access to care [1]. Every year, millions of emergency department (ED) visits in the United States (US) involve mental illness and substance use disorders [2]. Recent data from California indicate that nearly $30 \%$ patients seen in a ED had a prior mental health diagnosis [3]. The number of ED visits for primarily mental health reasons has increased markedly over past two decades [4]. For US adults under age 45, mental illness is the top reason for hospitalization [5]. In 2016, 7.7 million hospitalizations, accounting for $21.7 \%$ of national hospital stays, were attributable to mental and substance use disorders [6]. Linkage to and continuity of mental health care is a challenge, with persistent high suicide rates for mental health patients following hospital discharge [7].

Access to psychiatric care in the US is inequitable across communities due in part to an uneven distribution of psychiatrists, psychologists, and other mental health professionals [8]. A shortage of psychiatrists is more likely to occur in non-metropolitan counties than metropolitan counties; nearly $70 \%$ of counties in the West North Central Census Division lacked a licensed psychiatrist-a rate over tenfold higher than the New England Census Division where only $6 \%$ of counties had no psychiatrist [8]. Amid provider shortages, the national number of psychiatric beds declined from 0.31 to 0.21 beds per 1,000 population from 2000 to 2016 [9]. Limited access to psychiatric inpatient care may result in EDs being overcrowded with patients with psychiatric conditions [10], challenges for patient safety, and increased health care costs $[11,12]$. Meanwhile, lack of or loss to follow-up after psychiatric inpatient discharge can also lead to nonadherence to medications [13], readmission among high-risk patients, and even suicidality [14]. Specifically, the period between psychiatric discharge and follow-up is a particularly critical time for suicidal risk, with high rates of suicides occurring within one week of hospital discharge for psychiatric patients [15]. However, only $55.8 \%$ of hospitals delivered timely care following psychiatric hospitalization, with psychiatric specialty hospitals, public hospitals, and minorityserving hospitals reporting lower follow-up rates within 30 days post discharge [16].

Mental health advocates have advanced telepsychiatry as one possible solution to the shortage of mental health professionals [17-19]. Within a hospital setting, telepsychiatry may enable providers to complete virtual psychiatric evaluations, provide teletherapy, engage in brief communications and check-ins with patients, and provide patient education [20,21]. In addition, telepsychiatry may overcome some barriers to care by enabling patients to access mental health services from a private, trusted location. Telepsychiatry may also be an effective way to decrease ED visits for non-life-threatening mental health conditions and to ensure continuity of care for patients after being discharged from inpatient care. These virtual care systems have been proven to be well received by patients, associated with decreased admissions or readmissions to psychiatric hospitals, and cost effective [22]. In a pandemic like the coronavirus disease 2019 (COVID-19), use of telepsychiatry becomes essential to cope with the increasing mental health care demand nationwide, while implementing social distancing and other infection control and prevention measures [23].

While telehealth adoption has steadily increased nationwide, telepsychiatry has lagged behind [17, 18]. From 2010 to 2017 , the proportion of hospitals with any telehealth doubled from 35-76\% in the US [24]. Despite well-documented acceptance of telepsychiatry by patients and clinicians and higher perceived efficacy than standard care by patient populations [25-27], only about $20 \%$ of hospital-based EDs had telepsychiatry as of 2016 [28]. In 2013 , less than 1\% of rural Medicare beneficiaries reported ever having utilized telehealth for mental health services [29]. Telepsychiatry use was also uncommon among commercially insured populations, with only 0.5 telepsychiatry visits per 1,000 members per quarter in 2017 [30]. Even among mental health facilities, only about $30 \%$ offered telepsychiatry by 2017 [31]. Full implementation of telepsychiatry takes months, even for well-resourced hospitals [21]. As community 
mental health services have been reduced over the past decades [32], hospital-based services play an increased role in preventing and managing psychiatric crises, especially for patients with severe mental health disorders or being discharged from inpatient care. Assessing the distribution of telepsychiatry adoption across hospital settings is an essential first step to understand the availability of services and to identify areas and settings where gaps exist.

Prior work has demonstrated geographic variation in the availability of mental health resources across counties nationwide [33-35], and variations in telepsychiatry adoption in mental health facilities [31]. However, to our knowledge, no study has examined geographic distribution of telepsychiatry adoption across US hospitals. Much remains unknown about characteristics of hospitals that choose to adopt telepsychiatry, which is vital to identify where the shortages of telepsychiatry are and where to enact policies to support more rapid telepsychiatry adoption. Therefore, this study aimed to assess the geographic distribution of telepsychiatry across hospitals in the US; and investigate characteristics associated with telepsychiatry adoption.

\section{Methods}

\section{Data sources}

This study used three datasets to derive hospital- and county-level characteristics documented by previous literature [36]: 1) the 2017 American Hospital Association (AHA) Annual Survey, 2) the Area Health Resource File, and 3) hospital-level financial performance data from the Centers for Medicare \& Medicaid Services Healthcare Cost Report Information System. In 2017, the AHA Annual Survey had a hospital response rate of $85 \%$. In this study, we included 4,602 acute care hospitals that provided general medical or surgical care, psychiatric services, or pediatric psychiatric care, with included hospitals located in 50 states and Washington, DC. Hospitals in US territories were excluded due to large variations in policies and regulations. We then excluded 1,127 hospitals that did not provide a response to whether they had telepsychiatry, yielding 3,475 acute care hospitals in the final data set. Compared to the 1,127 excluded hospitals, included hospitals were more likely to have no inpatient or outpatient psychiatric services, to be federal hospitals or private non-profit hospitals, to be teaching hospitals, to be less profitable, and to be in counties with high uninsured rates and high poverty rates (Appendix Table 1). 
Table 1

Hospital and county-level characteristics by telepsychiatry adoption in 2017

\begin{tabular}{|c|c|c|c|c|}
\hline \multirow[t]{2}{*}{ Characteristics } & Number (\%) & Number (\%) & Number (\%) & $P$ \\
\hline & of Hospitals & $\begin{array}{l}\text { of Hospitals had } \\
\text { Telepsychiatry }\end{array}$ & $\begin{array}{l}\text { of Hospitals without } \\
\text { Telepsychiatry }\end{array}$ & \\
\hline Nationally & $\begin{array}{l}3,475 \\
(100.0)\end{array}$ & $548(15.8)$ & $2,927(84.2)$ & \\
\hline \multicolumn{5}{|l|}{ Hospital Location } \\
\hline Urban & $2,046(58.9)$ & $397(19.4)$ & $1,649(80.6)$ & $<0.001$ \\
\hline Rural Micropolitan & $602(17.3)$ & $82(13.6)$ & $520(86.4)$ & $<0.001$ \\
\hline Rural Noncore & $827(23.8)$ & $69(8.3)$ & 758 (91.7) & $<0.001$ \\
\hline \multicolumn{5}{|l|}{ Provision of Psychiatric Services } \\
\hline None of Inpatient and & $1,526(43.9)$ & $104(6.8)$ & $1,422(93.2)$ & $\begin{array}{l}<0.001< \\
0.001\end{array}$ \\
\hline \multicolumn{5}{|l|}{ Outpatient Psychiatric Services } \\
\hline Inpatient Psychiatric Services Only & $111(3.2)$ & $9(7.9)$ & $102(92.1)$ & 0.02 \\
\hline Outpatient Psychiatric Services Only & $814(23.4)$ & $124(15.2)$ & $690(84.8)$ & 0.63 \\
\hline $\begin{array}{l}\text { Both Inpatient and Outpatient Psychiatric } \\
\text { Services }\end{array}$ & $1,024(29.5)$ & $311(30.4)$ & $713(69.6)$ & $<0.001$ \\
\hline \multicolumn{5}{|l|}{ Ownership } \\
\hline Federal & $55(1.6)$ & $44(80.0)$ & $11(20.0)$ & $<0.001$ \\
\hline Non-federal Public & $731(21.0)$ & $92(12.6)$ & $639(87.4)$ & $<0.01$ \\
\hline Non-profit, Private & $384(11.1)$ & $33(8.6)$ & 351 (91.4) & $<0.001$ \\
\hline For-profit, Private & $2,305(66.3)$ & $379(16.4)$ & $1,926(83.6)$ & 0.13 \\
\hline System Affiliation & & & & $<0.001$ \\
\hline Yes & $2,337(67.3)$ & $423(18.1)$ & 1,914 (81.9) & \\
\hline No & $1,138(32.7)$ & $125(11.0)$ & $1,013(89.0)$ & \\
\hline Teaching Status & & & & $<0.001$ \\
\hline Yes & $1,508(43.4)$ & $341(22.6)$ & $1,167(77.4)$ & \\
\hline No & $1,967(56.6)$ & $207(10.5)$ & $1,760(89.5)$ & \\
\hline Critical Access Hospital & & & & $<0.001$ \\
\hline Yes & $1,003(28.9)$ & $81(8.1)$ & 922 (91.9) & \\
\hline No & $2,472(71.1)$ & $467(18.9)$ & $2,005(81.1)$ & \\
\hline \multicolumn{5}{|l|}{ Hospital Beds Staffed } \\
\hline $1-25$ & $1,034(29.8)$ & $76(7.4)$ & $958(92.7)$ & $<0.001$ \\
\hline $26-100$ & $800(23.0)$ & $112(14.0)$ & $688(86.0)$ & 0.12 \\
\hline $101-225$ & 747 (21.5) & $128(17.1)$ & $619(82.9)$ & 0.25 \\
\hline$>225$ & $894(25.7)$ & $232(26.0)$ & $662(74.1)$ & $<0.001$ \\
\hline \multicolumn{5}{|l|}{ Ratio of Medicaid Inpatient Days } \\
\hline \multicolumn{5}{|l|}{ to Total Inpatient Days } \\
\hline$\leq 7.76 \%$ & $887(25.5)$ & $105(11.8)$ & $782(88.2)$ & $<0.001$ \\
\hline $7.76 \% \%-16.67 \%$ & $1,048(30.2)$ & $134(12.8)$ & $914(87.2)$ & $<0.01$ \\
\hline $16.67 \%-23.61 \%$ & $729(21.0)$ & $131(18.0)$ & $598(82.0)$ & 0.07 \\
\hline$>23.61 \%$ & $811(23.3)$ & $178(22.0)$ & $633(78.0)$ & $<0.001$ \\
\hline
\end{tabular}

Notes: The P values are derived from Pearson's Chi-squared tests for the categorical characteristics (percentages) and from Kruskal-Wallis rank-sum tests for the numeric characteristics for the null hypothesis that hospitals with and without telepsychiatry are the same. 


\begin{tabular}{|c|c|c|c|c|}
\hline Characteristics & $\begin{array}{l}\text { Number (\%) } \\
\text { of Hospitals }\end{array}$ & $\begin{array}{l}\text { Number (\%) } \\
\text { of Hospitals had } \\
\text { Telepsychiatry }\end{array}$ & $\begin{array}{l}\text { Number (\%) } \\
\text { of Hospitals without } \\
\text { Telepsychiatry }\end{array}$ & $P$ \\
\hline Negative Margins & $879(25.3)$ & $104(11.8)$ & $775(88.2)$ & $<0.001$ \\
\hline Positive Margins & 2047 (58.9) & $314(15.3)$ & $1733(84.7)$ & 0.41 \\
\hline Missing & $549(15.8)$ & $130(23.7)$ & $419(76.3)$ & $<0.001$ \\
\hline \multicolumn{5}{|l|}{$\begin{array}{l}\text { County-level Population by Age Groups, } \\
\text { (Mean, Standard Deviation) }\end{array}$} \\
\hline$<15$ & $\begin{array}{l}19.0 \% \\
(0.026)\end{array}$ & $19.0 \%(0.026)$ & $18.7 \%(0.026)$ & 0.13 \\
\hline $15-24$ & $\begin{array}{l}13.3 \% \\
(0.031)\end{array}$ & $13.2 \%(0.031)$ & $13.7 \%(0.031)$ & $<0.001$ \\
\hline $25-44$ & $\begin{array}{l}27.4 \% \\
(0.036)\end{array}$ & $27.2 \%(0.036)$ & $28.3 \%(0.036)$ & $<0.001$ \\
\hline $45-64$ & $\begin{array}{l}26.3 \% \\
(0.029)\end{array}$ & $26.4 \%(0.030)$ & $25.9 \%(0.029)$ & $<0.001$ \\
\hline $65-74$ & $7.5 \%(0.019)$ & $7.6 \%(0.019)$ & $7.1 \%(0.019)$ & $<0.001$ \\
\hline$>75$ & $6.6 \%(0.021)$ & $6.6 \%(0.021)$ & $6.2 \%(0.021)$ & $<0.001$ \\
\hline \multicolumn{5}{|c|}{$\begin{array}{l}\text { County-level Population by Race/Ethnicity, \% } \\
\text { (Mean, Standard Deviation) }\end{array}$} \\
\hline Non-Hispanic White & $\begin{array}{l}69.9 \% \\
(0.219)\end{array}$ & $70.3 \%(0.220)$ & $67.5 \%(0.213)$ & $<0.001$ \\
\hline Non-Hispanic Black & $5.3 \%(0.064)$ & $5.1 \%(0.064)$ & $6.1 \%(0.063)$ & $<0.001$ \\
\hline American Indian and Alaska Native & $1.8 \%(0.052)$ & $1.8 \%(0.052)$ & $16.2 \%(0.054)$ & 0.03 \\
\hline Hispanic & $\begin{array}{l}13.3 \% \\
(0.155)\end{array}$ & $13.3 \%(0.158)$ & $13.0 \%(0.138)$ & 0.02 \\
\hline Other & $9.8 \%(0.094)$ & $9.4 \%(0.093)$ & $11.8 \%(0.976)$ & $<0.001$ \\
\hline \multicolumn{5}{|l|}{ County-level Population Uninsured, \% } \\
\hline$\leq 7.4 \%$ & $1,132(32.6)$ & $203(17.9)$ & $929(82.1)$ & 0.02 \\
\hline $7.4 \%-10.6 \%$ & $926(26.6)$ & $153(16.5)$ & $773(83.5)$ & 0.46 \\
\hline $10.6 \%-14.5 \%$ & $717(20.6)$ & $123(17.2)$ & $594(82.9)$ & 0.25 \\
\hline$>14.5 \%$ & $700(20.1)$ & $69(9.9)$ & $631(90.1)$ & $<0.001$ \\
\hline \multicolumn{5}{|c|}{$\begin{array}{l}\text { County-level Population Living in Poverty } \\
\text { ( }<200 \% \text { Federal Poverty Level), } \%\end{array}$} \\
\hline$\leq 26.43 \%$ & $1,063(30.6)$ & $199(18.7)$ & $864(81.3)$ & $<0.01$ \\
\hline $26.43 \%-32.58 \%$ & $1,064(30.6)$ & $164(15.4)$ & $900(84.6)$ & 0.70 \\
\hline $32.58 \%-39.20 \%$ & $812(23.4)$ & $124(15.3)$ & $688(84.7)$ & 0.66 \\
\hline$>39.20 \%$ & $536(15.4)$ & $61(11.4)$ & $475(88.6)$ & $<0.01$ \\
\hline \multicolumn{5}{|l|}{ County-level Population Unemployed, \% } \\
\hline$\leq 3.5 \%$ & $881(25.4)$ & $123(14.0)$ & $758(86.0)$ & 0.09 \\
\hline $3.5 \%-4.4 \%$ & $1,070(30.8)$ & $185(17.3)$ & $885(82.7)$ & 0.10 \\
\hline $4.4 \%-5.5 \%$ & $976(28.1)$ & $158(16.2)$ & $818(83.8)$ & 0.67 \\
\hline$>5.5 \%$ & $548(15.8)$ & $82(15.0)$ & $466(85.0)$ & 0.57 \\
\hline \multicolumn{5}{|l|}{ Designation as a Mental Health } \\
\hline No & $218(6.3)$ & $48(22.0)$ & $170(78.0)$ & $<0.01$ \\
\hline
\end{tabular}




\begin{tabular}{|lllll|}
\hline Characteristics & $\begin{array}{c}\text { Number (\%) } \\
\text { of Hospitals }\end{array}$ & $\begin{array}{l}\text { Number (\%) } \\
\text { of Hospitals had } \\
\text { Telepsychiatry }\end{array}$ & $\begin{array}{l}\text { Number (\%) } \\
\text { of Hospitals without } \\
\text { Telepsychiatry }\end{array}$ & $P$ \\
\hline Part & $1,676(48.2)$ & $334(19.9)$ & $1,342(80.1)$ & $<0.001$ \\
\hline Whole & $1,581(45.5)$ & $166(10.5)$ & $1,415(89.5)$ & $<0.001$ \\
\hline County-level Total Number of Psychiatrists & & & $1,183(90.4)$ & $<0.001$ \\
\hline None & $1,308(37.6)$ & $125(9.6)$ & $345(86.3)$ & $<0.001$ \\
\hline $1-4$ & $400(11.5)$ & $55(13.8)$ & $1,399(79.2)$ & $<0.001$ \\
\hline$>4$ & $1,767(50.8)$ & $368(20.8)$ & & 0.50 \\
\hline Census Region & & & $970(83.3)$ & 0.17 \\
\hline Northeast & $612(17.6)$ & $102(16.7)$ & $1,093(86.0)$ & 0.03 \\
\hline South & $1,146(33.0)$ & $167(14.6)$ & $345(77.3)$ & $<0.001$ \\
\hline Midwest & $1,271(36.6)$ & $178(14.0)$ & $101(22.7)$ & \\
\hline West & $446(12.8)$ & $101)$ & \\
\hline $\begin{array}{l}\text { Notes: The P values are derived from Pearson's Chi-squared tests for the categorical characteristics (percentages) and from Kruskal-Wallis rank-sum tests } \\
\text { for the numeric characteristics for the null hypothesis that hospitals with and without telepsychiatry are the same. }\end{array}$ \\
\hline
\end{tabular}

\section{Measures}

The primary outcome is whether a hospital adopted telepsychiatry in 2017. According to the AHA survey, telepsychiatry is defined as a type of telehealth defined as "a broader variety technologies and tactics to deliver virtual diagnosis and management, education, and other health care with telecommunications technologies [37]." In particular, telepsychiatry is considered to "involve a range of services including psychiatric evaluation, therapy, patient education, and medication management [37]."

Hospital Characteristics. Ownership, teaching status, system affiliation, designation as critical access hospital, hospital beds staffed, ratio of Medicaid inpatient days to total inpatient days, provision of in-person psychiatric services, and profit margins.

County Characteristics. Counties were grouped into urban, rural micropolitan (counties with an urbanized area of 10,000-49,999 residents), and rural noncore areas (all other counties), based on the US Department of Agriculture's Urban Influence Codes [38]. To identify county-level factors associated with telepsychiatry adoption, we included annual median household income, age groups, racial distribution of residents, rates of uninsured residents, unemployment rates, rates of population living in poverty (defined as $\leq 200 \%$ federal poverty line), whether the county where a hospital was located was designated as a mental health professional shortage area, and total number of psychiatrists.

\section{Statistical analyses}

We first mapped hospitals with telepsychiatry based on the latitudes and longitudes of their address using SAS version 9.4 [39]. Chi-squared tests and KruskalWallis rank-sum tests were used to compare hospital- and county-level characteristics across hospitals with and without telepsychiatry. Generalized logistic regression models were used to estimate marginal associations of each predictor on telepsychiatry adoption, with county-level clustering. Multicollinearity was assessed using variance inflation factors (VIF) that did not indicate the presence of multicollinearity among predictors (i.e., VIF $=2.90$ ). We selected the final model based on the lowest values of Akaike Information Criterion and Bayesian Information Criterion [40]. The final model included hospital location, provision of psychiatric services, ownership, system affiliation, hospital beds staffed, ratio of Medicaid inpatient days to total inpatient days, profit margins, county-level age group, race/ethnicity, rate of population uninsured, designation as mental health professional shortage areas, number of psychiatrists, and census region (Appendix Table 2-4). We also conducted sensitivity analyses by replacing county-level uninsured rate with county-level unemployed rate and rate of population living in poverty. All analyses were conducted using SAS version 9.4 and Stata version 14.0. The study protocol was reviewed and exempted by the [university] Institutional Review Board. 
Table 2

Marginal differences of hospital and county-level characteristics on telepsychiatry adoption

Characteristics
Average

Marginal Differences

\section{HOSPITAL CHARACTERISTICS}

\section{Hospital Location}

Urban

Rural Micropolitan

Rural Noncore

\section{Provision of Psychiatric Services}

None of Inpatient and Outpatient Psychiatric Services

Inpatient Psychiatric Services Only

Outpatient Psychiatric Services Only

Both Inpatient and Outpatient Psychiatric Services

\section{Ownership}

Non-federal Public

Private For-Profit

Private Non-Profit

Federal Hospitals

System Affiliation

No

Yes

Hospital Beds Staffed

$1-25$

$26-100$

$101-225$

$>225$

Ratios of Medicaid Inpatient Days to Total Inpatient Days

$\leq 7.76 \%$

$7.76 \%-16.67 \%$

$16.67 \%-23.61 \%$

$>23.61 \%$

\section{Profit Margins}

Negative Margins

Positive Margins

Missing

\section{COUNTY LEVEL CHARACTERISTICS}

County-level Population by Age Groups, Years *

$<15$

$15-24$

$25-44$

$45-64$
Ref

$0.1 \%$

$0.7 \%$

Ref

$1.1 \%$

$6.5 \%$

$16.0 \%$

$-5.1 \%$

$7.2 \%$

0.73

$3.7 \%$

$9.4 \%$

$<0.001$

$12.1 \%$

$19.9 \%$

$<0.001$

Ref

$-1.4 \%$

$-5.2 \%$

$2.4 \%$

0.46

$-6.9 \%$

$48.9 \%$

$-11.7 \%$

$-2.0 \%$

$<0.01$

$32.5 \%$

$65.3 \%$

$<0.001$

Ref

$3.9 \%$

$1.2 \%$

$6.6 \%$

$<0.01$

Ref

$2.4 \%$

$2.1 \%$

$6.2 \%$

Ref

$1.6 \%$

$3.1 \%$

$4.9 \%$

$-1.7 \%$

$6.4 \%$

0.25

$-2.7 \%$

$6.9 \%$

0.39

$0.7 \%$

$11.6 \%$

0.03 


\begin{tabular}{|c|c|c|c|c|}
\hline \multirow[t]{2}{*}{ Characteristics } & Average & $95 \% \mathrm{Cl}$ & & $P$ \\
\hline & \multicolumn{4}{|c|}{ Marginal Differences } \\
\hline $65-74$ & $4.1 \%$ & $-13.4 \%$ & $21.7 \%$ & 0.65 \\
\hline$>75$ & $1.1 \%$ & $-12.8 \%$ & $15.0 \%$ & 0.88 \\
\hline \multicolumn{5}{|c|}{ County-level Population by Race/Ethnicity \% † } \\
\hline Non-Hispanic White & Ref & & & \\
\hline Non-Hispanic Black & $-1.4 \%$ & $-4.5 \%$ & $1.8 \%$ & 0.39 \\
\hline American Indian and Alaska Native & $-0.7 \%$ & $-4.4 \%$ & $3.1 \%$ & 0.73 \\
\hline Hispanic & $-1.0 \%$ & $-2.1 \%$ & $0.1 \%$ & 0.08 \\
\hline Other & $-0.4 \%$ & $-2.5 \%$ & $1.7 \%$ & 0.72 \\
\hline \multicolumn{5}{|l|}{ County-level Population Uninsured, \% } \\
\hline$\leq 7.4 \%$ & Ref & & & \\
\hline $7.4 \%-10.6 \%$ & $1.6 \%$ & $-1.4 \%$ & $4.6 \%$ & 0.29 \\
\hline $10.6 \%-14.5 \%$ & $3.5 \%$ & $-0.7 \%$ & $7.6 \%$ & 0.10 \\
\hline$>14.5 \%$ & $2.0 \%$ & $-3.9 \%$ & $7.9 \%$ & 0.51 \\
\hline \multicolumn{5}{|c|}{ Designation as a Mental Health Professional Shortage Area } \\
\hline No & Ref & & & \\
\hline Part & $-5.2 \%$ & $-11.1 \%$ & $0.7 \%$ & 0.08 \\
\hline Whole & $-6.6 \%$ & $-12.7 \%$ & $-0.5 \%$ & 0.03 \\
\hline \multicolumn{5}{|c|}{ County-level Total Number of Psychiatrists } \\
\hline None & Ref & & & \\
\hline $1-4$ & $-2.6 \%$ & $-7.2 \%$ & $1.9 \%$ & 0.26 \\
\hline$>4$ & $-2.7 \%$ & $-7.6 \%$ & $2.2 \%$ & 0.28 \\
\hline \multicolumn{5}{|l|}{ Census Region } \\
\hline Northeast & Ref & & & \\
\hline South & $-1.9 \%$ & $-6.8 \%$ & $2.9 \%$ & 0.44 \\
\hline Midwest & $-1.0 \%$ & $-5.1 \%$ & $3.2 \%$ & 0.65 \\
\hline West & $-1.5 \%$ & $-6.6 \%$ & $3.7 \%$ & 0.59 \\
\hline
\end{tabular}

\section{Results}

\section{Distribution of telepsychiatry adoption across US hospitals}

Figure 1 illustrates the geographic distribution of telepsychiatry adoption across hospitals in the US. Of 3,475 hospitals, approximately $16 \%$ reported having telepsychiatry in 2017 (Table 1). Only 19.4\% of urban hospitals had adopted telepsychiatry, and far fewer hospitals in rural micropolitan (13.6\%) and rural noncore areas (8.3\%) did. However, approximately $32.3 \%$ (267 of 827 ) of urban counties had at least one hospital with telepsychiatry, compared to $16.0 \%$ (78 of 489 ) of rural micropolitan and $9.4 \%$ (69 of 737) of rural noncore counties. Hospitals in counties with lower proportions of residents living in poverty and uninsured residents were more likely to adopt telepsychiatry compared with hospitals in affluent counties. Hospitals in counties designated as mental health professional shortage areas, with smaller number of psychiatrists also reported lower levels of telepsychiatry adoption than their counterparts. The proportion of telepsychiatry adoption varied significantly by state (Appendix Fig. 1). Hospitals in Connecticut (47.6\%), Alaska (45.5\%) and North Carolina (41.8\%) had the highest rates of telepsychiatry adoption. No hospitals in Delaware reported telepsychiatry.

\section{Multivariate analysis of telepsychiatry adoption}

As shown in Table 2, after controlling for key covariates, rural micropolitan and rural noncore hospitals no longer differed from urban hospitals in telepsychiatry adoption. Hospitals with outpatient psychiatric services only (marginal differences [95\% Cl]: 6.5\% [3.7-9.4\%]), as well as hospitals that offered both outpatient and inpatient psychiatric care services (16.0\% [12.1-19.9\%]) had greater likelihood of telepsychiatry adoption than hospitals without designated psychiatric services. Compared to non-federal public hospitals, federal hospitals (48.9\% [32.5-65.3\%]) were more likely to have telepsychiatry, while private non-profit hospitals (-6.9\% [-11.7\% to $-2.0 \%)$ were less likely to have telepsychiatry. System affiliated hospitals (3.9\% [1.2-6.6\%]), large hospitals 
(Quartile IV of hospital beds staffed vs. Quartile I: 6.2\% [0.7-11.6\%]), hospitals with greater ratio of Medicaid inpatient days to total inpatient days (4.4\% [0.1$8.6 \%]$ ), and hospitals in counties with greater proportion of population aged $25-44$ years $(7.2 \%$ [0.4-14.0\%]) also reported greater likelihoods of having telepsychiatry. However, hospitals in mental health shortage counties were less likely to adopt telepsychiatry. Profit margins, county-level number of psychiatrists, racial distribution of residents, rate of uninsured residents, and US census region were not independently associated with telepsychiatry adoption in 2017.

In the sensitivity analysis, results were robust for other hospital and county characteristics (Appendix Table 4-5). Telepsychiatry adoption rates were not different across hospitals by county-level socioeconomic characteristics.

\section{Discussion}

Using nationwide hospital data, this study explored geographic variations in telepsychiatry adoption across US hospitals in 2017, and findings can inform efforts to improve access to psychiatric care and reduce persistent geographic disparities in mental health [17-19]. Our data indicate that less than one in six (15.8\%) hospitals had telepsychiatry as of 2017. This suggests that substantial challenges remain for increasing access to psychiatric services across the US Although the majority of rural residents live in mental health shortage areas, telepsychiatry is not routinely being used to deliver psychiatric services in these areas. Hospitals in rural noncore areas were far less likely to have adopted telepsychiatry - with only $8 \%$ of rural noncore hospitals having telepsychiatry in 2017. Telepsychiatry adoption varied significantly by both hospital- and county-level characteristics, including provision of outpatient psychiatric services, system affiliation, hospital bed size, ownership, ratio of Medicaid inpatient days to total inpatient days, and designation as mental health shortage areas.

Although telehealth has long been advocated as a tool to improve access to care and to facilitate the transition from hospital-based care to community-based care [41], we find that telepsychiatry adoption by hospitals remains very limited. More importantly, our study reveals that hospitals in counties with more psychiatrists did not have higher telepsychiatry adoption rates. Clinical resources that are clustered in certain geographic areas may have little benefit for individuals residing outside of those areas without purposeful, targeted efforts to expand access. This finding may be due to the absence of incentives, a lack of hospital buy-in, and/or limited education or training for psychiatrists to provide telepsychiatry in the hospital settings [27, 42]. In addition, many patients may face barriers to engaging in such services, particularly due to the persistent rural-urban disparities in high speed Internet access [43].

It is concerning that hospitals in rural counties have lower rates of telepsychiatry adoption, especially hospitals in noncore areas. While mental health facilities in rural noncore areas have greater rates of telepsychiatry than their urban counterparts [31], it is possible that administrators of local hospitals were not sufficiently motivated to expand telepsychiatry. One prior study has revealed that around $40 \%$ of individuals who died by suicide had received care within 30 days of their suicide [44]. In addition, poor continuity of care and lack of follow-up for individuals discharged from psychiatric inpatient settings are major issues $[7,45]$. Providing follow-up after psychiatric hospitalization discharge has proven useful to reduce risk of non-adherence to medication and suicide [13, 14]. Telepsychiatry may facilitate timely delivery of follow-up care after discharge and make it easier to support patients' adherence to treatment [16, 17].

Bridging these gaps calls for a wider availability of telepsychiatry to improve continuity of care. Our study reveals that hospitals with inpatient psychiatric services but without outpatient psychiatric services did not report greater adoption of telepsychiatry than their counterparts. This may be related to the per diem prospective payment system for inpatient psychiatric facilities and insufficient payment for outpatient services [46, 47]. Also, telepsychiatry adoption rates vary tenfold by facility operation, with $80 \%$ of federal hospitals but only $16 \%$ of non-federal public and $8.6 \%$ of private non-profit hospitals reporting telepsychiatry. This result is likely due to the significant progress that has been made by the Veteran Affairs system in promoting telehealth [48]. To ensure access to psychiatric care for all, federal and state policymakers should expand the types of providers eligible to receive reimbursements for both live video and remote patient monitoring for patients in need.

Our study demonstrates that hospitals with a greater ratio of Medicaid inpatient days to total inpatient days were more likely to have telepsychiatry. This suggests that federal Medicaid policies could promote telepsychiatry adoption in these hospitals; surprisingly, profit margins were not independent factors associated with telepsychiatry use, even though investing in telehealth systems is perceived as a way to increase the competitive advantage of a hospital [49]. This might be related to decreasing trends in average reimbursement for telepsychiatry [50]. In 2018, over 10 states still did not have parity legislation in place for private insurance coverage of telehealth [51]; these telepsychiatry disparities are likely historically rooted, in part, in regulation and reimbursement policies. Policies to improve access to care through expanded telehealth are evolving quickly as a result of the COVID-19 pandemic; however, the public and private funding sources that will be needed for expanded telehealth remain unclear [52].

With the increasing demands in psychiatric services, our findings on lower rates of telepsychiatry adoption in counties designated as mental health professional shortage areas raises concerns about access to care for residents in these already low resource areas. Lack of telepsychiatry adoption in vulnerable communities is likely compounded by the limited supply of mental health professionals to begin with. Without purposeful state and federal efforts to address the inequitable distribution of mental health resources, disparities in access to care are likely to persist. These results call for allocating telepsychiatry funding based on local mental health care need. Otherwise, residents in these counties will be less likely to have access to evidence-based treatments for mental health disorders, and the health disparities affecting the rural US are likely to persist or even worsen.

This study has some limitations. First, the AHA Annual Survey asked about hospital-wide use of telepsychiatry via a single item without querying the extent of use or scope of services offered. About $25 \%$ of hospitals did not respond to the item on telepsychiatry. Assuming that hospitals without any telehealth tend not to respond to telehealth questions, the current national rate of telepsychiatry adoption may be overestimated. Second, our cross-sectional data did not allow us to make causal inferences, and we had no data about local psychiatric care needs. Third, our study focused on the telepsychiatry adoption at hospital settings, which include EDs, as well as inpatient and outpatient psychiatric services. We did not include mental health facilities in our analysis though they often provide a broad range of services [53]. This study documented the telemedicine availability prior to COVID-19, which might have uptick during the 
pandemic [54]. Future study may expand on the current baseline measures and investigate how linkages between hospital and community-based systems can be forged and strengthened, in order to close the access gaps for residents in vulnerable communities.

\section{Conclusions}

This study is the first to examine the national geographic distribution of telepsychiatry adoption across US hospitals and the hospital characteristics that were associated with adoption. Significant regional and rural-urban disparities of hospital-based telepsychiatry adoption exist. Understanding the distribution of telepsychiatry adoptions and associated factors is vital to enact targeted policies to improve access to hospital-based inpatient and outpatient psychiatric care for those in need. This study found that factors related to both hospital capacity and external environments were important predictors of telepsychiatry adoption. Our results highlight disproportionate barriers facing rural, isolated, small, and freestanding hospitals to adopting telepsychiatry. Given welldocumented benefits of telepsychiatry, policies and enhanced funding are needed to ensure necessary infrastructure in small and less-resourced hospitals to ensure access to psychiatric care among residents, especially those in mental health professional shortage areas.

\section{Abbreviations}

ED

Emergency department;

AHA

American Hospital Association;

AIC

Akaike Information Criterion;

BIC

Bayesian Information Criterion;

COVID-19

Coronavirus Disease 2019

\section{Declarations}

\section{Ethics approval and consent to participate}

Not applicable.

\section{Consent for publication}

Not applicable.

\section{Availability of data and materials}

The datasets used and analyzed during the current study are available from the corresponding author on reasonable request.

\section{Competing interests}

The authors declare that they have no competing interests.

\section{Funding}

This study was sponsored by the [author's university], Office of the Vice President for Research. The funding source had no role in the design and conduct of this study; data collection, management, analysis and interpretation; preparation, review and approval of the manuscript; and decision to submit the manuscript for publication. The content is solely the responsibility of the authors and does not necessarily represent the official view of the [author's university] Office for Research.

\section{Authors' contributions}

Dr. Hung and Mr. Z Li had full access to all the data in the study and take responsibility for the integrity of the data and the accuracy of the data analysis. Study concept and design: Hung, Z Li. Acquisition, analysis, or interpretation of data: all authors. Drafting of the manuscript: Z Li, Hung. Critical revision of the manuscript for important intellectual content: Hung, X Li, Harrison. Statistical analysis: Z Li, Hung. Obtained funding: Hung. Study supervision: Hung, X Li.

\section{Acknowledgements}


Not applicable.

\section{References}

1. Substance Abuse and Mental Health Services Administration. Key substance use and mental health indicators in the United States: Results from the 2017 National Survey on Drug Use and Health (HHS Publication No. SMA 18-5068, NSDUH Series H-53). Rockville, MD: Center for Behavioral Health Statistics and Quality. https://www.samhsa.gov/data/. Accessed May 5,2020.

2. Owens PL, Mutter R, Stocks C. Mental health and substance abuse-related emergency department visits among adults, 2007: Statistical Brief\# 92. 2010. https://www.hcup-us.ahrq.gov/reports/statbriefs/sb92.pdf. Accessed May 5,2020.

3. Niedzwiecki MJ, Sharma PJ, Kanzaria HK, et al. Factors associated with emergency department use by patients with and without mental health diagnoses. JAMA Network Open. 2018;1(6):e183528-8.

4. Capp R, Hardy R, Lindrooth R, Wiler J. National trends in emergency department visits by adults with mental health disorders. J Emer Med. 2016;51(2):131-5.

5. Healthcare Cost and Utilization Project. HCUP Fast Stats - Most Common Diagnoses for Inpatient Stays.2017 U.S. National Inpatient Stays: Age 18-44 Years.2017. https://www.hcup-us.ahrq.gov/faststats/NationalDiagnosesServlet?

year $1=2017 \&$ characteristic $1=22 \&$ included $1=1$ \&year $2=\&$ characteristic $2=0 \&$ included $2=1$ \&expansionlnfoState=hide \&dataTablesState=hide \&definitionsState Accessed May 5,2020.

6. Owens PL, Fingar KR, McDermott KW, et al. Inpatient stays involving mental and substance use disorders, 2016: Statistical brief\# 249. 2019. https://www.ncbi.nlm.nih.gov/books/NBK540878/. Accessed May 5,2020.

7. Chung DT, Ryan CJ, Hadzi-Pavlovic D, et al. Suicide rates after discharge from psychiatric facilities: a systematic review and meta-analysis. JAMA psychiatry. 2017;74(7):694-702.

8. Andrilla CHA, Patterson DG, Garberson LA, et al. Geographic variation in the supply of selected behavioral health providers. Am J Prev Med. 2018;54(6):199-207.

9. Organization for Economic Co-operation and Development. Health Care Resource: Psychiatric care beds. https://stats.oecd.org/Index.aspx? ThemeTreeld=9. Accessed May 5,2020.

10. Nesper AC, Morris BA, Scher LM, et al. Effect of decreasing county mental health services on the emergency department. Ann Emerg Med. 2016;67(4):525-30.

11. Volkow ND, Jones EB, Einstein EB, et al. Prevention and treatment of opioid misuse and addiction: a review. JAMA psychiatry. 2019;76(2):208-16.

12. Kessler RC, Heeringa S, Lakoma MD, et al. Individual and societal effects of mental disorders on earnings in the United States: results from the national comorbidity survey replication. Am J Psychiatry. 2008;165(5):703-11.

13. Tiihonen J, Haukka J, Taylor M, et al. A nationwide cohort study of oral and depot antipsychotics after first hospitalization for schizophrenia. Am J Psychiatry. 2011;168(6):603-9.

14. Olfson M. Suicide risk after psychiatric hospital discharge. JAMA psychiatry. 2017;74(7):669-70.

15. Bickley H, Hunt IM, Windfuhr K, et al. Suicide within two weeks of discharge from psychiatric inpatient care: a case-control study. Psychiatr Serv. 2013;64(7):653-9.

16. Benjenk I, Chen J. Variation of Follow-Up Rate After Psychiatric Hospitalization of Medicare Beneficiaries by Hospital Characteristics and Social Determinants of Health. Am J Geriatr Psychiatry. 2019;27(2):138-48.

17. O'Reilly R, Bishop J, Maddox K, et al. Is telepsychiatry equivalent to face-to-face psychiatry? Results from a randomized controlled equivalence trial. Psychiatr Serv. 2007;58(6):836-43.

18. Fortney JC, Pyne JM, Kimbrell TA, et al. Telemedicine-based collaborative care for posttraumatic stress disorder: a randomized clinical trial. JAMA psychiatry. 2015;72(1):58-67.

19. Mechanic D. Removing barriers to care among persons with psychiatric symptoms. Health Aff (Millwood). 2002;21(3):137-47.

20. Graziane JA, Gopalan P, Cahalane J. Telepsychiatry consultation for medical and surgical inpatient units. Psychosomatics. 2018;59(1):62-6.

21. Grady B, Singleton M. Telepsychiatry “coverage" to a rural inpatient psychiatric unit. Telemed J E Health. 2011;17(8):603-8.

22. Salmoiraghi A, Hussain S. A systematic review of the use of telepsychiatry in acute settings. J Psychiatr Pract. 2015;21(5):389-93.

23. Shore JH, Schneck CD, Mishkind MC. Telepsychiatry and the Coronavirus Disease 2019 Pandemic-Current and Future Outcomes of the Rapid Virtualization of Psychiatric Care. JAMA psychiatry. 2020. doi:10.1001/jamapsychiatry.2020.1643.

24. American Hospital Association. Fact Sheet: Telehealth. 2019. https://www.aha.org/system/files/2019-02/fact-sheet-telehealth-2-4-19.pdf. Accessed May 5,2020 .

25. Fortney JC, Pyne JM, Mouden SB, et al. Practice-based versus telemedicine-based collaborative care for depression in rural federally qualified health centers: a pragmatic randomized comparative effectiveness trial. Am J Psychiatry. 2013;170(4):414-25.

26. Bashshur RL, Shannon GW, Bashshur N, et al. The empirical evidence for telemedicine interventions in mental disorders. Telemed J E Health. 2016;22(2):87-113.

27. Rollman BL, Belnap BH, Abebe KZ, et al. Effectiveness of online collaborative care for treating mood and anxiety disorders in primary care: a randomized clinical trial. JAMA psychiatry. 2018;75(1):56-64.

28. Freeman RE, Boggs KM, Zachrison KS, et al. National study of telepsychiatry use in US emergency departments. Psychiatr Serv. 2020;71(6):540-6. 
29. Mehrotra A, Jena AB, Busch AB, et al. Utilization of telemedicine among rural Medicare beneficiaries. JAMA. 2016;315(18):2015-6.

30. Barnett ML, Ray KN, Souza J, et al. Trends in telemedicine use in a large commercially insured population, 2005-2017. JAMA. 2018;320(20):2147-9.

31. Spivak S, Spivak A, Cullen B, et al. Telepsychiatry use in US mental health facilities, 2010-2017. Psychiatr Serv. 2020;71(2):121-7.

32. Hung P, Busch SH, Shih YW, et al. Changes in community mental health services availability and suicide mortality in the US: a retrospective study. BMC Psychiatry. 2020;20:1-12.

33. Ellis AR, Konrad TR, Thomas KC, et al. County-level estimates of mental health professional supply in the United States. Psychiatric Services. 2009;60(10):1315-22.

34. Cummings JR, Wen H, Ko M,et al. Geography and the Medicaid mental health care infrastructure: implications for health care reform. JAMA psychiatry. 2013;70(10):1084-90.

35. Cummings JR, Allen L, Clennon J, et al. Geographic access to specialty mental health care across high-and low-income US communities. JAMA psychiatry. 2017;74(5):476-84.

36. Laura J, Damschroder DC, Aron, Rosalind E, Keith, et al. Fostering implementation of health services research findings into practice: a consolidated framework for advancing. Implement Sci. 2009;4(1):50.

37. American Hospital Association. AHA Annual Survey Database. Fiscal Year 2017. https://www.ahadata.com/aha-annual-survey-database. Accessed May 5,2020 .

38. United States Department of Agriculture Economic Research Service. Urban Influence Codes. 2019. https://www.ers.usda.gov/data-products/urbaninfluence-codes.aspx. Accessed May 5,2020.

39. Zdeb M, Rensselaer N. The Basics of Map Creation with SAS/GRAPH. SUGI 29. 2004.

https://support.sas.com/resources/papers/proceedings/proceedings/sugi29/251-29.pdf. Accessed May 5, 2020.

40. Burnham KP, Anderson DR. Multimodel inference: understanding AIC and BIC in model selection. Sociol Methods Res. 2004;33(2):261-304.

41. Lin CCC, Dievler A, Robbins C. Telehealth in health centers: key adoption factors, barriers, and opportunities. Health Aff (Millwood). 2018;37(12):1967-74.

42. Yellowlees P, Nafiz N. The psychiatrist-patient relationship of the future: anytime. anywhere? Harv Rev Psychiatry. 2010;18(2):96-102.

43. Whitacre BE, Mills BF. Infrastructure and the rural-urban divide in high-speed residential Internet access. Int Reg Sci Rev. 2007;30(3):249-73.

44. Luoma JB, Martin CE, Pearson JL. Contact with mental health and primary care providers before suicide: a review of the evidence. Am J Psychiatry. 2002;159(2):909-16.

45. Moffitt TE, Caspi A. Psychiatry's opportunity to prevent the rising burden of age-related disease. JAMA psychiatry. 2019;76(5):461-2.

46. Centers for Medicare \& Medicaid Services. Payment for Outpatient Services Provided to Beneficiaries Who Are Inpatients of Other Facilities. 2019.

47. https://. Accessed May 5,2020.

48. Centers for Medicare \& Medicaid Services. Inpatient Psychiatric Facility Prospective Payment System (IPF PPS) PC PRICER. 2020.

https://www.cms.gov/Medicare/Medicare-Fee-for-Service-Payment/PCPricer/inppsy. Accessed May 5,2020.

49. Adams SV, Mader MJ, Bollinger MJ, et al. Utilization of interactive clinical video telemedicine by rural and urban veterans in the Veterans Health Administration health care system. J Rural Health. 2019;35(3):308-18.

50. Adler-Milstein J, Kvedar J, Bates DW, et al. Telehealth among US hospitals: several factors, including state reimbursement and licensure policies, influence adoption. Health Aff (Millwood). 2014;33(2):207-15.

51. Wilson FA, Rampa S, Trout KE, et al. Telehealth delivery of mental health services: an analysis of private insurance claims data in the United States. Psychiatr Serv. 2017;68:1303-6.

52. American Telemedicine Association. State with Parity Laws for Private Insurance Coverage of Telemedicine (2018).

53. http://legacy.americantelemed.org/main/policy-page/state-policy-resource-center\#.VjQqLZ3D_IU. Accessed May 5,2020.

54. Center for Medicare \& Medicaid Services. Telehealth services. 2020. https://www.cms.gov/Outreach-and-Education/Medicare-Learning-NetworkMLN/MLNProducts/downloads/TelehealthSrvcsfctsht.pdf. Accessed May 5,2020.

55. Department of Health and Human Services Substance Abuse and Mental Health Services Administration FY 2020 Certified Community Behavioral Health Clinic Expansion Grants

Department of Health and Human Services Substance Abuse and Mental Health Services Administration. FY 2020 Certified Community Behavioral Health Clinic Expansion Grants. https://www.samhsa.gov/sites/default/files/grants/pdf/fy-2020-ccbhc-foa.pdf.

56. Accessed. May 5,2020.

57. Das LT, Gonzalez CJ. Preparing Telemedicine for the Frontlines of Healthcare Equity. J Gen Intern Med. 2020. https://doi.org/10.1007/s11606-020-059419.

\section{Supplementary Files}

This is a list of supplementary files associated with this preprint. Click to download.

- Additionalfile.docx 